\title{
Competitive effects for the adsorption of copper, cadmium and lead ions using modified activated carbon from bamboo
}

\author{
Jherwin Ocreto ${ }^{1}$, Chester Ian $\mathrm{Go}^{1}$, Jans Cholo Chua ${ }^{1}$, Cyrrus Jude Apacible ${ }^{1}$, Anabella Vilando ${ }^{1, *}$ \\ ${ }^{1}$ Department of Chemical Engineering, College of Engineering, Adamson University, 900 San Marcelino St, Ermita Manila, 1000 \\ Metro Manila, Philippines
}

\begin{abstract}
Modified activated carbon from bamboo was used as a low-cost potential adsorbent to remove cadmium, copper and lead in single, bimetal and trimetal aqueous solutions. Using the initial concentration of $40 \mathrm{ppm}$, the analysis was conducted to determine the effect of $\mathrm{pH}(2.5,3.0$, and 5.5), contact time (60, 90, $120 \mathrm{~min}$ ) and adsorbent dosage (20,40,60 mg/50 mL of solution). Results showed that for single metal aqueous solution, the \% adsorption for $\mathrm{Cu}, \mathrm{Cd}$, and $\mathrm{Pb}$ were $89.0 \%, 87.4 \%$, and $99.5 \%$ respectively. For bimetal aqueous solution the \% adsorption of $\mathrm{CuCd}, \mathrm{CuPb}, \mathrm{CdCu}, \mathrm{CdPb}, \mathrm{PbCu}$,and $\mathrm{PbCd}$ were $90.6 \%$, $98.9 \%, 55.1 \%, 80.7 \%, 99.6 \%$, and $96.05 \%$, respectively. While for trimetal aqueous solutions, $\%$ adsorption of $\mathrm{Cu}, \mathrm{Cd}$, and $\mathrm{Pb}$ were $87.4 \%, 73.0 \%$, and $98.4 \%$, respectively. The \% removal uptake followed the order $\mathrm{Pb}>\mathrm{Cu}>\mathrm{Cd}$ gave insights into competition effects among the three solutes during the adsorption process. Using Box-Behnken Design, the effect $\mathrm{pH}$ of the aqueous solution is an important controlling parameter in which the $\%$ adsorption increased as the $\mathrm{pH}$ level is increased while other parameters were insignificant.
\end{abstract}

\section{Introduction}

Water pollution by heavy metals discharged from industrial effluents has become a worldwide problem during recent years, as most heavy metal species have toxic effects on organisms and accumulate in biota which does not undergo biological decay thus they are much harder to remove [1].

The long-term use of wastewater in agricultural land results in the contamination of soils by toxic heavy metals. These heavy metals include: zinc ( $\mathrm{Zn})$, cadmium $(\mathrm{Cd})$, copper $(\mathrm{Cu})$, nickel $(\mathrm{Ni})$, lead $(\mathrm{Pb})$, manganese $(\mathrm{Mn})$, iron $(\mathrm{Fe})$, mercury $(\mathrm{Hg})$, and chromium $(\mathrm{Cr})[\mathbf{2}, \mathbf{3}]$. Various toxic heavy metals affect the production and quality of crops and potentially influence the quality of water bodies. It threatens the life of terrestrial, aquatic animals and health of humans by food chain cycle $[4,5]$. But, the most severe is the kind of pollution it can produce in a long-term and non-reversible.

Hence, to be able to sustain the water, there is a need for careful and planned management. To address the negative impacts it may arise, the use of activated carbon for adsorption of toxic heavy metals can respond to this problem.

Today, activated carbon is a multibillion-dollar manufacturing industry and researchers are continue developing this using local materials. The long-term availability of coal, environmental impacts and potentially increasing cost have encouraged researchers to find an alternative that is cost effective and equally potential. Activated carbon can be manufactured from any organic material that has reasonable elemental carbon content. Any lignocellulose material can be converted to an activated carbon [6].

This research produced a modified activated carbon from local bamboo using two-step carbonization and impregnation process. The optimal parameters for the adsorption of heavy metals at different operating conditions in a single metal, bimetal and trimetal solutions were evaluated using Box-Behnken Design (BBD).

\section{Materials and methods}

\subsection{Preparation of the adsorbents}

A phosphoric acid were prepared in the ratio of $60: 40$ phosphoric acids and water [7]. This mixture was mixed thoroughly in a 40:60 ratio with bamboo feedstock ( $>$ 4.00 in) and allowed to undergo hydrolysis overnight. The hydrolyzed solid was burned at $100^{\circ} \mathrm{C}$ for half hour followed by $400{ }^{\circ} \mathrm{C}$ for one hour to produce a good quality char. The produced carbon char was ground with a mortar and pestle and sieved to a workable particle size range of 70-100 mesh. The char was washed with $0.1 \mathrm{M}$ $\mathrm{HCl}$ and kept in a desiccator for a day to ensure that no air is absorbed. The char/chemical activating agent mixture was prepared to fill roughly the $30 \%$ of the beaker volume. For large scale activation conducted to obtain the mass balance, the activating agent was added to the char in a 3:1 char: activating agent $(\mathrm{KOH})$ ratio with impregnation time of 24 hours [7-10]. The resulting

* Corresponding author: anabella.vilando@adamson.edu.ph 
mixture was mixed in beaker with a mass of distilled water less than or equal to the mass of the carbon char until a paste like mixture was formed. The samples were kept in the furnace for a process hold time of 1 hour at a process temperature of $800^{\circ} \mathrm{C}$ [10-12]. $\mathrm{KOH}$ activation process was used after it was heated. The activated mixtures were transferred and washed in a Buchner funnel to remove the potassium from the carbon. Each sample was washed with $1 \mathrm{~L}$ of distilled water [8]. The carbon was then kept in desiccators overnight to dry. After drying, it was weighed to determine the process yield and put in sealed dry polyethene bags.

\subsection{Preparation of metal concentrations}

For a single metal, aliquots of $50 \mathrm{ml} \mathrm{of} \mathrm{Pb}, \mathrm{Cu}$, and $\mathrm{Cd}$ aqueous solutions of $40 \mathrm{ppm}$ concentration were prepared separately. For bimetal combination, aliquots of $50 \mathrm{ml}$ of $\mathrm{Pb}$ and $\mathrm{Cd}, \mathrm{Cd}$ and $\mathrm{Cu}$, and $\mathrm{Cu}$ and $\mathrm{Pb}$ aqueous solutions with a 50:50 volume ratio of metal were prepared separately. Aliquots of $50 \mathrm{ml}$ for a trimetal combination are being prepared with a volume ratio of 1/3:1/3:1/3 for $\mathrm{Pb}, \mathrm{Cu}$, and $\mathrm{Cd}$.

\subsection{Preparation of samples}

Batch adsorption was performed at a room temperature. A mass of $20 \mathrm{mg}, 40 \mathrm{mg}$, and $60 \mathrm{mg}$ of adsorbate was added to each metal solutions of $50 \mathrm{ml} \mathrm{[12-14]}$. The $\mathrm{pH}$ of each solution was adjusted to $2.5,4.0$ and 5.5 by adding a few drops of $\mathrm{NaOH}$ or $\mathrm{HCl}$ solution (prior to the addition of the adsorbent) [14-16]. The flasks was capped and shaked in an agitator at $100 \mathrm{rpm}$ for at different contact time of $60 \mathrm{~min}, 90 \mathrm{~min}$ and $120 \mathrm{~min}$ to attain the equilibrium condition $[\mathbf{1 1}, \mathbf{1 7}]$. Then, the solutions above was be filtered and the residual metal concentration was determined using the Atomic Absorption Spectrophotometer.

The main parameters derived from the adsorption experiments were \% removal or adsorption capacity of copper, cadmium and lead. The percent removal of heavy metal ions will be calculated according to Eq. (1).

$$
\% \text { Removal }=\frac{C_{0}-C_{e}}{C_{0}} x 100
$$

where $C_{0}=$ heavy metal initial concentration, $C_{e}=$ heavy metal final concentration

\subsection{Statistical design}

The experimental data were analyzed using a statistical software Design Expert 8 using Response Surface Design to study the variables that may affect the results of the study. The optimum conditions were evaluated using BBD.

\section{Results and discussion}

\subsection{Characterization of the bamboo char}

The surfaces of the modified raw material (Fig. 1) showed cavities, pores, few cracks or voids and more rough surfaces on the activated carbon. Different sizes of granular pores and cavities were produced that increased the surface area of the adsorbent. High porosity was observed on the external surface of the bamboo char. These pores resulted from the evaporation of the chemical reagent $\left(\mathrm{H}_{3} \mathrm{PO}_{4}\right)$ during carbonization, leaving empty spaces which can hold more solute from solution during adsorption $[\mathbf{1 8 , 1 9 ]}$.

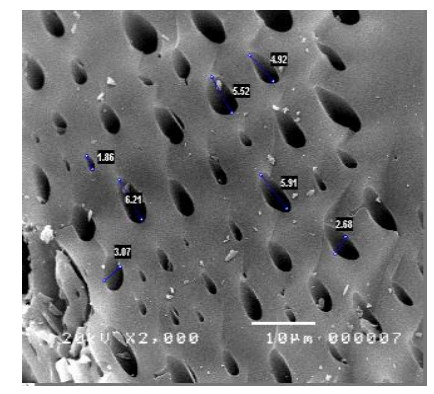

(a)

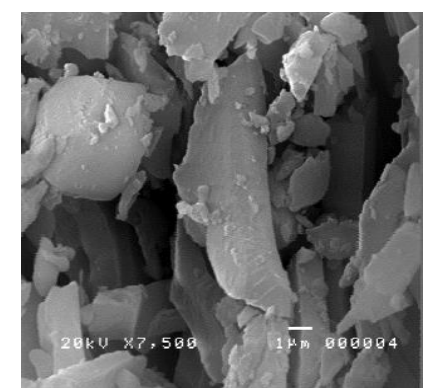

(b)
Figure 1. SEM image of $\mathrm{KOH}$ activated carbon at (a) 2000 and (b) 7500 magnification.

\subsection{Effects of $\mathrm{pH}$}

\subsubsection{Single metal}

Based from Fig. 2a, it can be observed that increasing the $\mathrm{pH}$ increased the \% adsorption of $\mathrm{Cu}, \mathrm{Cd}$, and $\mathrm{Pb}$ for mono component adsorption also increased. A higher percentage of adsorption of the metal ions can be achieved by increasing the $\mathrm{pH}$ level of the solution up to 5.5. It can be seen that $\mathrm{Pb}$ exhibits higher \% removal than $\mathrm{Cu}$ and $\mathrm{Cd}$. The highest removal was achieved at $\mathrm{pH}$ value of 5.5 having the \% adsorption for $\mathrm{Cu}, \mathrm{Cd}$, and $\mathrm{Pb}$ as $89.0 \%, 87.4 \%$, and $99.5 \%$ respectively.

\subsubsection{Bimetal}

Fig. 2b showed that the \% adsorption in bimetallic solutions increased as the $\mathrm{pH}$ level was increased from 2.5 to 5.5. The highest \% adsorption of $\mathrm{CuPb}$ in a bimetallic solution was shown while $\mathrm{CuCd}$ was the least. Peak values was achieved at $\mathrm{pH} 5.5$ at which the \% adsorption of $\mathrm{CuCd}, \mathrm{CuPb}, \mathrm{CdCu}, \mathrm{CdPb}, \mathrm{PbCu}$, and PbCd were $90.6 \%, 98.9 \%, 55.1 \%, 80.7 \%, 99.6 \%$, and $96.1 \%$ respectively.

\subsubsection{Trimetal}

The results from Fig. 2c, showed the \% removal uptake followed the order of $\mathrm{Pb}>\mathrm{Cu}>\mathrm{Cd}$ which gave insight into competition effects among the three solutes. The $\%$ 
adsorption in tri metallic solution increased as the $\mathrm{pH}$ level was increased from 2.5 to 5.5 . It can also be seen that $\mathrm{Pb}$ in multicomponent solute achieved the highest \% adsorption and $\mathrm{Cd}$ came the least. The $\mathrm{Pb}$ was removed with higher $\%$ than the other two metals, corresponding to the fact that the $\mathrm{Pb}$ has the greatest hydrated radii; moreover $\mathrm{Pb}$ had the greatest electronegativity. Since the activated carbon is negatively charged, the potential of the electrostatic adsorption among the three adsorbate increased directly proportional to their electronegativity [15].

Overall, the $\mathrm{pH}$ of the aqueous solution is an important controlling parameter in the adsorption process and thus the role of $\mathrm{H}^{+}$concentration was examined from samples at different range of $\mathrm{pH}$ values [19]. The $\mathrm{pH}$ of the samples was limited to 5.5; this is because at $\mathrm{pH}$ level beyond 5.5 resulted to the decrease in $\%$ adsorption due to the formation of soluble hydroxyl complexes. At low $\mathrm{pH}$ values the surface of the adsorbent would be closely associated with hydroxonium ions $\left(\mathrm{H}_{3} \mathrm{O}^{+}\right)$by repulsive forces to the surface functional groups, consequently decreased the \% removal of the metal. When the $\mathrm{pH}$ of the adsorbing medium was increased from 2.5 to 5.5 , there was an increase in the deprotonation of the adsorbent surface, leading to a decrease in the hydroxonium ions $\left(\mathrm{H}_{3} \mathrm{O}^{+}\right)$on the adsorbent surface. This created more negative charges on the adsorbent surfaces [20,21].

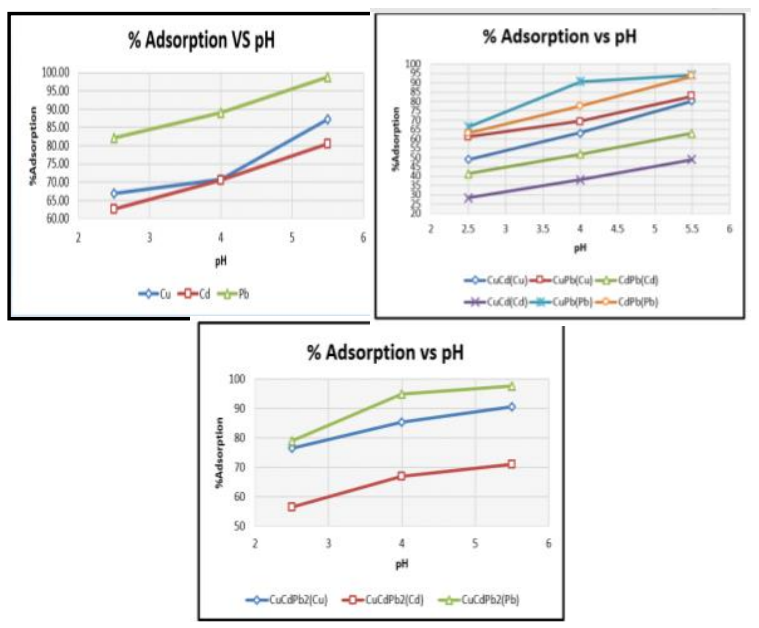

Figure 2. Effect of $\mathrm{pH}$ on metal adsorption in single, bimetal and trimetal component solution.

\subsection{Effects of pH}

\subsubsection{Single metal}

In Fig. 3a, the data showed that the single metal solutions' average \% adsorption of copper, cadmium and lead, varied at different contact times and exhibited different responses at any given parameter of contact time.

Also based on the range selected for the design, best single component metal adsorption was achieved at a contact time of 90,90 and $60 \mathrm{~min}$ at $89.0 \%, 97.4 \%$ and $99.5 \%$ adsorption.

\subsubsection{Bimetal}

Based from Fig. 3b, the range selected for the design, optimum binary component metal adsorption in solutions $\mathrm{CuCd}(\mathrm{Cu}), \mathrm{CuPb}(\mathrm{Cu}), \mathrm{CuCd}(\mathrm{Cd}), \mathrm{CdPb}(\mathrm{Cd}), \mathrm{CuPb}(\mathrm{Pb})$ and $\mathrm{CdPb}(\mathrm{Pb})$ was achieved at a contact time of 120,60 , $60,90,60$ and 90 minutes at which $90.6 \%, 98.8 \%$ $52.1 \%, 80.7 \% 99.6 \%$ and $98.8 \%$ was adsorbed.

\subsubsection{Trimetal}

The 73.7\% highest adsorption of was shown in Fig. 3c obtained for the adsorption of copper, cadmium and lead in trimetal component solutions at contact time of 120 $\min$. A $66.2 \%$ adsorption at contact time of $60 \mathrm{~min}$ and a $90.3 \%$ adsorption at contact time of $120 \mathrm{~min}$ were observed.

\subsection{Effects of dosage}

\subsubsection{Single metal}

In Fig. 4a, the data showed that the single metal solutions' average $\%$ adsorption of copper, cadmium and lead, varied at different carbon dosages exhibited different responses at any given parameter of carbon dosage. Based on the range selected for the design, optimum single component metal adsorption for copper, cadmium and lead was achieved at a carbon dosage of $0.02,0.06,0.04$ with $89.0 \%, 97.4 \%$ and $99.5 \%$ adsorbed.

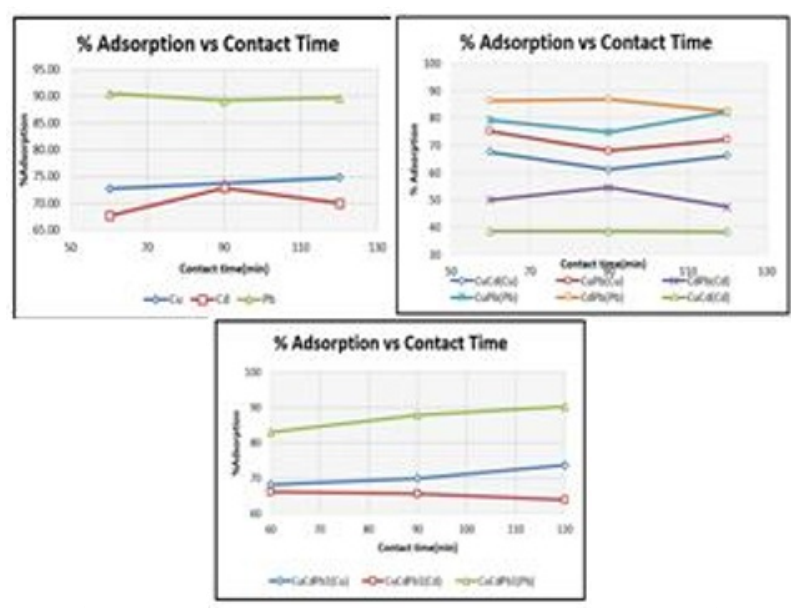

Figure 3. Effect of contact time on metal adsorption in single, bimetal and trimetal component solution.

\subsubsection{Bimetal}

From Fig. 4b showed the optimum binary component metal adsorption for copper, cadmium, and lead in $\mathrm{CuCd}(\mathrm{Cu}), \mathrm{CuPb}(\mathrm{Cu}), \mathrm{CuCd}(\mathrm{Cd}), \mathrm{CdPb}(\mathrm{Cd}), \mathrm{CuPb}(\mathrm{Pb})$ and $\mathrm{CdPb}(\mathrm{Pb})$ was achieved at a carbon dosage of 0.04 , $0.06,0.04,0.06,0.04$ and 0.02 having 90.6\%, 98.8\%, 
$52.1 \%, 80.7 \%, 99.6 \%$ and $98.8 \%$ of metal ions was adsorbed.

\subsubsection{Trimetal}

Based from Fig.4c the range selected for the single component metal adsorption for copper, cadmium and lead in a trimetal solution of $\mathrm{CuCdPb}$ was achieved at a carbon dosage of $0.04,0.04$, and 0.06 at which $87.4 \%$, $73.0 \%$ and $95.9 \%$ was adsorbed.

\subsection{Interactions}

It can be observed from Fig. 5 the interactions of different parameters on each graph. Figure 5-a illustrated the $\%$ adsorption as response in $\mathrm{Pb}$ in $\mathrm{CdPb}$ solution with fixed carbon dosage of 0.04 at varying parameters of $\mathrm{pH}$ and contact time are dependent to one another. The \% adsorption of lead in $\mathrm{CdPb}$ solution increased with increasing $\mathrm{pH}$ at contact time of $60 \mathrm{~min}$. In Fig. $\mathbf{5 b}$, the

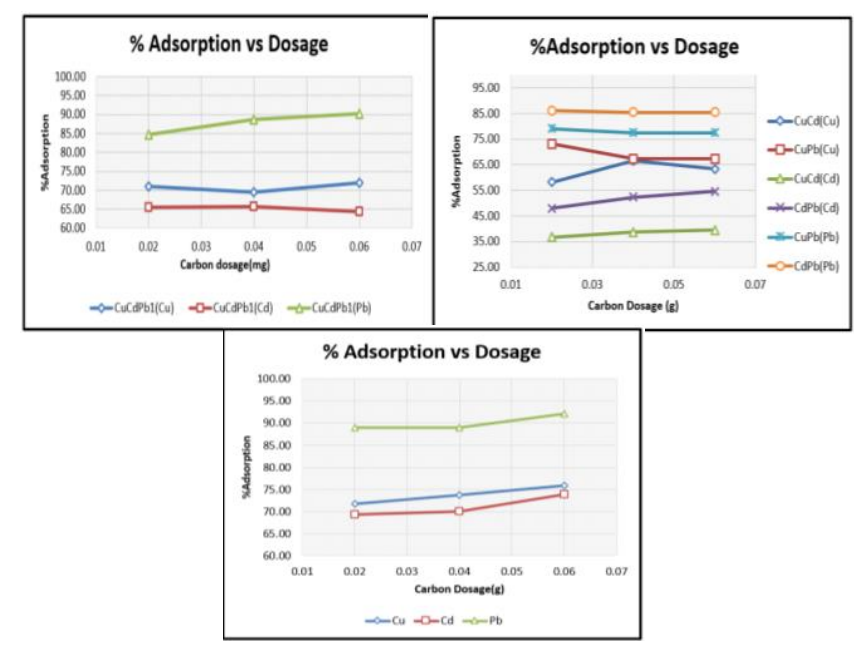

Figure 4. Effect of dosage on metal adsorption in single, bimetal and trimetal component solution.

dosage has an effect on time in the adsorption of $\mathrm{Cu}$ in a multicomponent solute in a solution. Increase in dosage yielded an increase in the $\%$ adsorption at $60 \mathrm{~min}$ while the mean response ( $\%$ adsorption) at maximum time of 120 min decreased. At increasing time of contact of 120 min, a great decreased of $\mathrm{pH} 5.5$ was observed. For Fig. 5c, increasing the $\mathrm{pH}$ from 2.5 to 5.5 yielded an increase in the $\%$ adsorption at minimum dosage of 0.02 grams while the mean response (\% adsorption) at maximum dosage of 0.06 grams decreased the at $\mathrm{pH}$ 5.5. In Fig. 5d, the $\%$ adsorption was slightly lowered by increasing the $\mathrm{pH}$ at a time of $120 \mathrm{~min}$ as compared to minimum time of $60 \mathrm{~min}$. In Fig. 5-e interactions between dosage and contact time at points along 0.05 to 0.06 . It can be observed from Fig. 5-f, that the $\mathrm{pH}$ has a significant effect over time in the adsorption of $\mathrm{Cd}$ in multicomponent solution. Increasing the $\mathrm{pH}$ from 2.5 to 5.5 yielded a higher $\%$ adsorption at minimum contact time of $60 \mathrm{~min}$, while the mean response (percent adsorption) at maximum time of $120 \mathrm{~min}$ was greatly decreased at $\mathrm{pH} 5.5$.
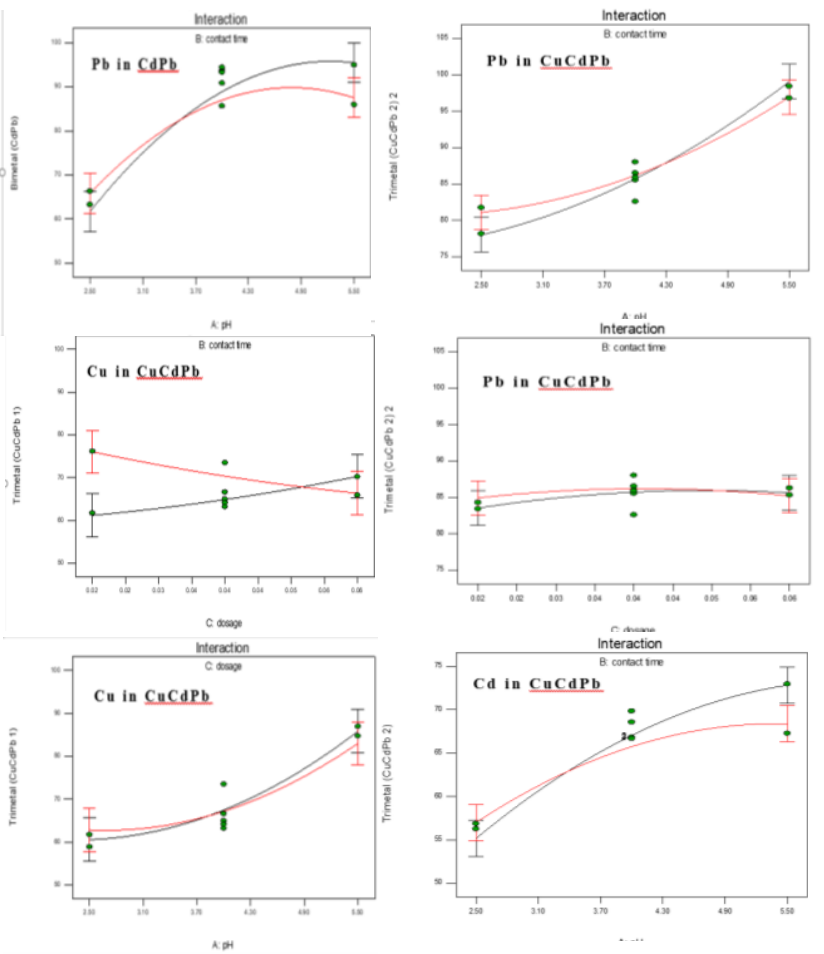

Figure 5. Interaction between $\mathrm{pH}$, contact time and dosage.

\section{Conclusion}

The adsorption characteristics of the modified activated carbon from bamboo were tested using aqueous solutions from a single metal, bimetal and trimetal solutions. Results showed that for single metal aqueous solution, \% adsorption for $\mathrm{Cu}, \mathrm{Cd}$, and $\mathrm{Pb}$ were $89.0 \%$, $87.4 \%$, and $99.5 \%$ respectively. For bimetal aqueous solution the \% adsorption of $\mathrm{CuCd}, \mathrm{CuPb}, \mathrm{CdCu}, \mathrm{CdPb}$, $\mathrm{PbCu}$ and $\mathrm{PbCd}$ were 90.6\%, 98.9\%, 55.1\%, 80.7\%, $99.6 \%$, and $96.1 \%$ respectively. While for trimetallic aqueous solution, the \% adsorption of $\mathrm{Cu}, \mathrm{Cd}$, and $\mathrm{Pb}$ was $87.4 \%, 73.0 \%$, and $98.4 \%$ respectively. The results of these experiments showed that the order of $\mathrm{Pb}>\mathrm{Cu}>$ $\mathrm{Cd}$ gave an insight in the competition effects among the three solutes during the adsorption process. Adsorption capacities in the mixture were reduced from their singlesolute values for all metals. Using $\mathrm{BBD}$, the $\%$ adsorption increased as the $\mathrm{pH}$ values increased from 2.5 to 5.5. While the contact time and carbon dosage showed insignificance. At any point within the range of these two parameters does not affect the optimum \% removal of the heavy metals. In terms of optimal parameters $\mathrm{Cu}$, $\mathrm{Cd}$, and $\mathrm{Pb}$ were validated with a $\%$ error of $2.4 \%, 2.2 \%$, and $1.6 \%$ respectively. This means that the efficiency of the optimization process was acceptable.

The authors extend its gratitude to the faculty and staff of the Department of Chemical Engineering for making this research possible. 


\section{References}

[1] Ali, I., 2010. The quest for active carbon adsorbent substitutes: inexpensive adsorbents for toxic metal ions removal from wastewater. Sep. Purif. Rev. 39, 95-171.

[2] Dougherty, T.C., Hall, A.W., 1995. Environmental impact assessment of irrigation and drainage projects. FAO Irrigation and Drainage Paper 53.

[3] Masona, C., Mapfaire, L., Mapurazi, S., Makanda, I., 2011. Assessment of Heavy Metal Accumulation in Wastewater Irrigated Soil and Uptake by Maize Plants (Zea Mays L) at Firle Farm in Harare. J. Sust. Dev. 4(6), 132-137.

[4] Postel, S.L., Daily, G.C., Ehrlich, P.R., 1996. Human appropriation of renewable fresh water. Science 271, 785-787.

[5] Pimentel, D., Berger, B., Filiberto, D., Newton, M., Wolfe, B., Karabinakis, E., Clark, S., Poon, E., Abbett, E., Nandaopal, S., 2004. Water Resources, Agriculture, and the Environment. Ithaca (NY): New York State College of Agriculture and Life Sciences, Cornell University. Report 04-1.

[6] Qureshi, K., Bhatti, I., Kazi R., Ansari, A.K., 2007. Physical and Chemical Analysis of Activated Carbon Prepared from Sugarcane Bagasse and Use for Sugar Decolorisation. World Acad. Sci, Eng. Tech. 34, 194198.

[7] Leimkuehler, E.P., 2010. Production, Characterization, and Applications of Activated Carbon. University of Missouri--Columbia.

[8] Sivakumar, V., Asaithambi, M., Sivakumar, P., 2012. Physico-chemical and adsorption studies of activated carbon from Agricultural wastes. Adv. App. Sci. Res. 3(1), 219-226.

[9] Bernardo, E.C., Egashira, R., Kawasaki, J., 1997. Decolorization of Molasses' Wastewater Using Activated Carbon Prepared From Cane Bagasse. Carbon 35, 1217.

[10] Cobb, A., Warms, M., Maurer, E., Chiesa, S., 2012. Low-Tech Coconut Shell Activated Charcoal Production. International Journal for Service Learning in Engineering 7(1), 93-104.

[11] Mahanim, S.M.A., Asma, I., Rafidah, J., Puad, E., Shaharuddin, H., 2011. Production of Activated Carbon From Industrial Bamboo Wastes. J. Trop. Forest Sci. 23(4), 417-424.

[12] Tangjuank, S., Insuk, N., Udeye, V., Tontrakoon, J., 2009. Chromium (III) sorption from aqueous solutions using activated carbon prepared from cashew nut shells. Int. J. Phy. Sci. 4(8), 412-417.

[13] Rani, S.A.F., Vimala, J.R., Bhuvana, T., 2012. Studies on the removal of nickel(II) using chemically activated pouteria sapota seed and commercially available carbon. Der Chem. Sin. 3(3), 613-620.

[14] Onundi, Y.B., Mamun, A.A., Al Khatib, M.F., Ahmed, Y.M., 2010. Adsorption of copper, nickel and lead ions from synthetic semiconductor industrial wastewater by palm shell activated carbon. Int. J. Environ. Sci. Tech 7(4), 751-758.

[15] El Zayat, M., Edward Smith, E., 2009. Removal of Heavy Metals by Using Activated Carbon Produced from Cotton Stalks. The American University in Cairo School of Sciences and Engineering.

[16] Wu, S., Chen, J.P., 2010. Modification of a commercial activated carbon for metal adsorption by several approaches.

[17] Wilsom, K., Yang, H., Seo, C.W., Marshall, W.E., 2006. Select metal adsorption by activated carbon made from peanut shells.. Bioresour. Technol. 97(18), 2266-2270.

[18] Deng, H., Li, G.X., Yang, H.B., Tang, J.P., Tang, J.Y., 2010. Preparation of activated carbons from cotton stalk by microwave assisted $\mathrm{KOH}$ and $\mathrm{K}_{2} \mathrm{CO}_{3}$ activation. Chem. Eng. J. 163, 373-381.

[19] Deng, H., L. Yang, L., Tao, G., Dai J., 2009. Preparation and characterization of activated carbon from cotton stalk by microwave assisted chemical activation-application in methylene blue.

[19] Baes, C.F., Mesmer, R.S., 1976. The Hydrolysis of Cations. John Wiley \& Sons, New York, London, Sydney, Toronto 489.

[21] Ghanem, S.A., Mikkelsen, D., 1988. Sorption of Zinc on Iron Hydrous Oxide. 